\title{
Water governance: a policy risk perspective
}

\author{
P. Martin \& J. Williams \\ Australian Centre for Agriculture and Law, \\ University of New England Australia
}

Contemporary management science embraces the analysis and management of risk of strategic or operational failure within the mainstream. Indeed, a failure to do so will, in most circumstances, be considered a failure of governance that may well be legally actionable. However, even in the face of powerful evidence that policy failure (fully or to some degree) is a normal element of water and other natural resource governance, public policy fails to contemplate and manage for this high probability contingency. Drawing on engaged and applied research conducted as part of the CRC Irrigation Futures institutional research program, meta-analysis commissioned by the Murray Darling Basin Authority, an international colloquium on water and conflict, and reviews of legal arrangements for water management, this paper considers the forms of risk of water policy failure, and mechanisms that might be effective in bringing water governance in line with at least the most basic standards of management and governance that apply in the private sphere.

Keywords: policy failure, governance, policy risk assessment, political risk, instrumental risk, spillover risk.

\section{Introduction}

With the global population expected to rise to around 9 billion by 2050 [1] and the consumption of natural resources tipping beyond the carrying capacity of the earth since 1980 [2], natural resource governance is perhaps the most important area of public policy on the planet, imperative for future human survival. Policy failure (fully or to some degree) is a normal element of natural resource governance however, are we learning from our policy failures to date or are we continually repeating the same dysfunctional patterns? As repetitive policy failures appear globally in water [3, 4], biofuels $[5,6]$, biodiversity $[7,8]$ and agriculture $[9,10]$ it appears that public policy is failing to contemplate and manage for this high probability contingency. Focusing on water governance, this paper explores the different forms of risk of policy failure and the 
mechanisms that might be effective in bringing natural resource governance in line with at least the most basic standards of management and governance that apply in the private sphere. We introduce our methodology of assessing the risk of natural resource policies developed as part of the CRC for Irrigation Futures 'Social, Cultural Institutional and Policy' (SCIP) research during 2007 to 2010. Whilst still in its early stages of development, policy risk assessment offers an effective tool for policy makers to explore the potential risks of a policy intervention prior to adoption and implementation.

\section{Water governance failures}

Integrated Water Resource Management (IWRM) has been the predominant paradigm globally since the 1990s to determine how water is managed and how water law should be reformed [11]. However, this approach relied largely on hydrology and economics, an optimization approach to attempt to balance economic and ecological interests [12, 13], often incorporating a variety of market instruments with the results frequently at odds with the intended sustainable water outcomes [14]. This reliance, solely on hydrology and economics, offers an indistinct view of the complexity of the issues and increases the likelihood of perverse outcomes from policies originally intended to ensure sustainable water management [15]. To demonstrate such unexpected perverse outcomes the following discussion will explore water governance failures firstly, viewing water law through the lens of conflict (exploring various international examples) followed by an overview of the Australian experience in the Murray Darling Basin. These examples serve to introduce the three main forms of policy risk: political risk, instrumental risk and spillover risk.

\subsection{Water law: through the lens of conflict}

In early 2011 a colloquium was held in Australia to uncover the challenges for water governance internationally, with water law explored through the lens of conflict. Water law, which differs in response to the various economic, social and environmental challenges of each jurisdiction, has globally faced significant challenges in achieving the intended outcomes of sustainable water management. Both water governance and legal scholarship offer a means to provide new insights into different ways to address these challenges. Conflict over water is a global issue, requiring a body of laws and norms to reflect the diverse, complex and evolving community values around water. The colloquium identified that the diversity of values of the community is incompletely reflected in the current mainstream water policy paradigm [15]. Qun [16] reports that water pollution events in China has resulted in new initiatives in national law and policy in response to social conflict around water pollution, government accountability, entities liability and citizens rights. However, compliance and enforcement is lacking from these initiatives and the challenge remains to effectively reduce water pollution accidents and resolve water pollution conflict. For example, China's pursuit of economic prosperity is given higher priority than 
environmental protection reflected in ineffective economic incentives, such as allowing construction of heavy industrial factories close to water sources and setting fees for polluted discharge and penalties for violations of environmental law substantially less than the costs to remedy the losses and recovery of water function. Fines under environmental law in China are considered to be vague and insufficient to deter violating conducts. Benson [17] reports the failure of law to protect public water uses in Western United States, where water conflicts arise from competition between traditional economic uses (such as irrigation, hydropower and municipal supply) and public uses (in particular environmental protection). This case study demonstrates how existing development-based water uses are protected and favoured, with water law making no real effort to revisit or improve these established water uses or to give higher status to public values. Despite political commitments to the environment, the actual legal instruments fail to protect the public values of environment and water-based recreation. Fort [18] supports this in a discussion on climate change and agriculture water use in Western United States finding that the current legal systems supports the status quo water uses, despite the growing pressures on ecosystems and groundwater, highlighting the need for re-examination of irrigation in arid regions in particular in the light of climate change impacts.

Tafur [19] offers insights of the South American perspective of water law, questioning whether water law and environmental legal frameworks are fit to deal with the pressures of hydropower and mining activities. The region has encountered large-scale expansion of mining over the last decade, with the mining and energy sectors regaining dominance as the key economic players. Tafur [19] presents examples of conflict between water users in both a mining and hydropower project revealing weaknesses in the regulatory system, with public uses, in particular the environment and community, disadvantaged. Strengthening is required in the Environmental Impact Assessment (EIA) processes in particular mechanisms to ensure water resources are adequately assessed, protected and monitored, improved public participation and better coordination between the water management allocation regimes and the environmental impact assessment of projects. Implementation and enforcement of monitoring and mitigation measures are required for the life of the projects. Water issues in South Africa that contribute to conflict [20] include water shortages (present and future), water quality (in particular impacts from sewerage, waste water pollution and acid mine drainage) and provision of basic water for human vitality. A lack of leadership contributes to the on-going conflict reflected in the poor management of wastewater; lack of skills; limitations of new laws in addressing poor past practices and a lack of political will demonstrated by a failure of Government to utilise their full legal powers to address the various sources of water pollution. Martin and Becker [21] explore the evolution of water law in both Australia and the United States demonstrating how water management allocation, originally an English common law domain is no longer the universal principle in either country. Water is allocated through a hybrid system consisting of complex government-led administrative allocation, trade via markets and limited use of civil action. Whilst it can be assumed that 
the scientific modernistic approach that prioritises economics and hydrology has influenced this evolution in water law, Martin and Becker [21] argue that conflict resolution within constitutional and institutional structures from earlier nonwater conflict contribute a substantial part in the evolution of water rules in both countries. Whilst water scarcity, economics and hydrology has influenced policy choices in both countries to some extent, this has differed within each country and between each country and highlights how politics and law might have a much greater hand in shaping water governance.

At the core of exploring water law through the lens of conflict are issues of social conflict involving property rights in water [22]. Jeffery and Craig [23] highlight the complexity of environmental law due to its close association with sustainable development (which includes social, political, economic and environmental aspects) making water conflicts highly complex and less likely to be mediated using Alternative Dispute Resolution (ADR). They propose that a more comprehensive approach to environmental dispute resolution is required, using a complementary mix of ADR mechanisms and litigation. Paisley and Grzybowski [24] further this discussion proposing a range of dispute resolution mechanisms that may have applicability in international waters governance agreements including: international courts, standing regional courts, tribunals and ad hoc arbitration.

\subsection{Evolution of water law in Australia}

Australia's water law has evolved from Federation in 1901 from a civil riparian system with water licences tied to land (and allocated by Government) to the relatively new system of extraction entitlements untied to land tradable through water access entitlement trade [25]. Environmental water is now managed through recognising environmental water in statutory water plans; secure water entitlements for the environment; the establishment of environmental water managers with appropriate authority and resources and developing environmental water accounting system [26]. Martin and Becker [21] argue that the structure of water law and administration in Australia reflects the fiscal force for collaboration between the states and the Commonwealth governments via cooperative federalism as demonstrated in the Council of Australian Government (COAG) agreements of 1994 and 2004. Coupled with the cooperative federalism approach to water management was the program nationally to move towards catchment wide water plans informed by best available science, socio-economic analysis and public participation that would determine the sustainable water allocations. These water sharing plans, undertaken by state government agencies ideally were intended to resolve conflicts, however, inconsistencies between compliance, tardiness of implementation of the 'National Water Initiative' and concern of ecological collapse of Australia's largest river system the Murray Darling Basin during a national drought led to the establishment of the Water Act 2007 (Cth). This Commonwealth act gave powers to a new authority (the Murray Darling Basin Authority) to develop a cross-jurisdictional basin wide plan, which both the Commonwealth and basin states are to implement. Conflict has arisen and continues around aligning water user interests and state water planning 
processes with the basin wide plan. In amongst this tangled water governance was the creation of 56 regional NRM bodies since 2002 (having varied responsibilities and legal structures across the jurisdictions), with these organisations providing a mechanism for the Commonwealth to overcome constitutional limitations to enable funding of specific projects in certain regions and states, thereby exercising direct control. These regional NRM bodies, having no clear authority in relation to water management, had great interest in issues of water quality and quantity within their catchment based plans. These overlaying catchment based plans and governance structures have created, and continue to create institutional complexity and high transaction costs. These multi-layered bodies and plans demonstrate that the origins of water law and institutions in Australia are very much shaped by the institutional arrangements put in place to negotiate the Australian federated system rather than addressing a particular natural resource management issue.

\subsubsection{Murray darling basin: review from a social and economic perspective}

Martin [27] undertook a meta-review of the specialists' reviews of the original 'Draft of the Guide to the Proposed Basin Plan' [28] and questioned whether the reviews and the draft Basin Plan actually addressed the legal obligation to consider socioeconomic and community as designated by Section 10 of the Water Act 2007 (Cth). This was reflected largely by the lack of discussion on people or communities (in particular indigenous) and the lack of consideration of the risks of perverse socioeconomic outcomes. The purpose of the plan is assumed to be an optimization of environmental and economic values with social values to the level of Basin communities, however it fails to acknowledge social optimisation or consider the community. A lack of monitoring and evaluation of socioeconomic issues at the community level was present instead relying on the macro level modelling. The inability to quantify cultural or other values of water limited the ability of the plan to take these into account. These were subsequently incorporated as environment flows. Economic analysis did not engage with the human aspects of community, instead was concerned with markets and modelling and potential cost shifting impacts to Local Government was not addressed. The guide discussion does attempt to incorporate social impact, however the discussion was shallow translating community into 'headcount' and 'production' and socioeconomics into economics. There was no substantive review of social impact evaluation with a lot of the socioeconomic data gathered to very little effect. There was a lack of socioeconomic risk assessment instead having a focus on risk to water and economic flows. One would assume it would be a fundamental imperative to consider how Basin interventions may aggravate the problems for communities, (in particular indigenous) in the Basin, however this was lacking. The peer reviews were constrained by time and data, of note the terms of reference (which included long and short term economic, environmental, social and equitable considerations and consideration of issues for Basin communities) was not reflected in the consultants' brief. In particular there was a glaring omission of indigenous cultural values in the reviews and in the guide. The potential implications for 
communities were not developed in various reviews where model issues were raised. Issues of social distribution of costs and benefits were also not considered and there was concern about mechanisms for broader community to be involved in operating rules. The process proposed for the basin plan was highly complex with a strong focus on models raising concerns about social justice, economic effectiveness and high transaction costs issues. The review of the reviews and the draft plan itself did not reflect the legislated expectation of triple bottom line aspects of community (in particular indigenous) had been taken into account with concern expressed that it would be 'difficult for MDBA to argue that the socioeconomic considerations have been treated as anticipated by the drafters of the Water Act' [27].

\subsection{Hubris in water law}

Legend tells of a Roman general who kept company with a slave whose job was to whisper in his ear as he walked the streets 'respice te, hominem te memento' (look behind you, remember you are only but a man) [29]. The jurisprudential and political traditions of the rule of law seek to limit the hubris of the powerful. Such attempts are characterised well in major law reforms (such as water law) where the powerful argue that trusting their unencumbered judgement would maximise social and even moral good, and that restricting them would result in loss to the community. Traditionally the lack of equality and political accountability of the law has resulted in healthy community scepticism of the claims of the privileged to superior knowledge and trustworthiness. The desire to impose accountability of the privileged can be seen in contemporary laws such as those protecting the privacy of the citizen, providing improved access to information, or enforcing administrative accountability. An increasingly activist public media joins in holding the commercial, political and scientific elites accountable. Three forces: democracy, the law and the media notionally stand with the Roman slave warning of the hubris of the powerful. The evolution of water governance in Australia, culminating in the Water Act 2007 (Cth) provides an example where lawyers and policy makers, motivated by the desire to find efficient ways to manage conflicts between ecology and economy, have unknowingly allowed the erosion of the safeguards against hubris. In pursuing this desirable end of efficient resource management has delivered surprisingly perverse outcomes of new policy risks, constraint of the effective rule of law, and reduced democratic accountability. Market instruments brings largely unquestioned economic and scientific orthodoxy that supports secure private property rights and the dominance of science-based modelling central to setting the boundaries and basic conditions for resource exploitation. In response to this paradigm governments create 'un-attenuated' property rights secure for substantial periods based on preferred forms of science (systems modelling) as the basis for key decisions. Such a process entrenches the interests of those to be defined as owners, and embedding those scientists whose models are selected, as the insiders in the system. Pursuing certainty and low transaction costs involves reducing perceived 'minor' matters that could make uncertain the fundamentals of the property-based system. By default this creation of certainty requires de- 
legitimating some potentially relevant interests and processes, creating new classes of 'insider' and 'outsider' as is evident from the meta-review of the basin plan. Recent developments in the law and related arrangements governing water markets in Australia introduces a risk of hubris with insufficient safeguards either against scientific error, or the exclusion of matters that become defined as 'outsider' interests. This criticism is not aimed to decry the use of market instruments, they have value and importance as essential elements of natural resource governance, however in the use of market instruments for the environment we need to understand better what these risks might be, and to create more effective means to safeguard against them. The environmental legal academy has an important role in identifying the risks, and to suggest legal and institutional means to guard against them even at the risk of raising issues that may be threatening or messy to the advocates of the marketplace and science. To believe that water conflict in the Basin is about the environment or irrigation is too simplistic, issues such as indigenous cultural interests are particularly relevant to the Basin as there is a substantial representation of Aboriginal people in the Basin. Conflicts between land management and water management (such as the newly evolving mining versus agriculture) and rural/urban water allocation, are highly likely and it is of concern that constraints imposed by the Water Act 2007 (Cth) may distort how conflict is managed and resolved. The role of the law is traditionally to provide a fair legal mechanism for conflict, and the role of Parliament is to provide a fair political mechanism for intervening to support social interests. The legal means to contest social priorities, individual interests and specialist opinions have been limited in the Water Act 2007 (Cth). Scientific hydrologic, ecologic or economic models that underpin administrative decisions should be legally contestable where they might adversely impact on citizens or public interests, and Parliament should have latitude to intervene, the courts to hear contests. Limiting the potential for legal intervention raises the prospect that untested (and possibly incorrect) modelling and decision-making may be implemented without transparent testing. This may result in environmental, social and economic harms that could be circumvented through better public scrutiny and testing of these matters. Hubris married to power has long been recognised as dangerous to the public interest. There is a need for lawyers to ensure that concern for the rule of law and the rights of the citizen do not become diminished in the pursuit of efficient means, even where the ends sought are as important as ecological sustainability or economic efficiency [30].

\subsection{Policy risk typologies}

For a policy to be successful it needs to firstly align sufficiently with formal and informal power structures (to avoid political impediments). Secondly, the strategy design and implementation must be sufficient to achieve the desired result (appropriate instruments) with any negative impacts (spillovers) from implementing the policy within acceptable bounds [31]. The examples of water governance from across the world and in Australia in our earlier discussion clearly demonstrate the three types of policy risk being political, instrumental and spillover risks. The risk of political opposition occurs when a successful 
sustainability policy may fail to be acceptable to those essential to its adoption or implementation, and therefore not be effectively deployed. For example political agents may either withhold formal authorisation or essential implementation resources or distort the policy substantially from the original design. Agency processes may also subvert the formal approval through peer groups' resistance, structural impediments to implementation or withholding essential resources. Equally powerful community interests can frustrate the policy through political opposition or disengagement. Those targeted by the policy can also impede the process through disengagement and active opposition to implementation. The risk of instrument failure occurs when an instrument might be adopted and supported yet fails to achieve its goals, with many examples of market instruments, regulations, environmental taxation and behaviour change in the water sector demonstrating such risk. Instrumental risk refers to the possibility that the chosen policy instruments are unsuitable or that the strategy for implementing the various instrumental choices will be insufficient for the task. The two main risk factors identified for instruments include: institutional credibility and efficiency (where markets and regulatory instruments require efficient legal and administrative systems trusted by the community), and transacting efficiency. In jurisdictions where institutional integrity and trust are low, the risk of instrumental failure increases, with high transaction costs further increasing the probability of policy failure. This risk of spillovers can occur when a policy will be implemented but cause unacceptable levels of unintended harms having spillover effects on vulnerable groups or causing unanticipated harm to the environment, or excessive economic costs. To manage spillover risks requires anticipation of indirect effects of changes triggered by a policy with an emphasis on the vulnerable groups and environments that may be affected. Common themes appear from our synthesis of water law, with evidence of policy failures evident due to political risks [17, 18, 20], instrumental risks [16, 19, 23, $24]$ and negative impact or spillover risks [16, 27, 30]. The following discussion will provide a brief overview of the policy risk assessment methodology developed as part of the CRC Irrigation Futures SCIP research in Western Sydney.

\section{Policy risk assessment}

Through our work with the CRC for Irrigation Futures there became a need for a process to test the risk of water policy options developed as part of the 'System Harmonization' program. The purpose of this research was to provide a participative risk-framing approach to improved risk sensitivity in the design of policy; use this process to discuss (with a particular emphasis on Australian water policy) some aspects of policy failures and/or spillovers, and from that experience, demonstrate how a disciplined policy risk approach can assist in creating more robust sustainability policy. The research resulted in the development of a Policy Risk Assessment Manual [31] to guide policy risk assessment in the first stage of analysis of the risks of policy proposals. This manual was used in Western Sydney to assess the policy risks of three possible 
water supply interventions of: storm-water harvesting and reuse, effluent reuse and smart farms project. Figure 1 provides an overview of the process (see Martin and Williams [31] for more detailed information on the methodologies that underpin the framework).

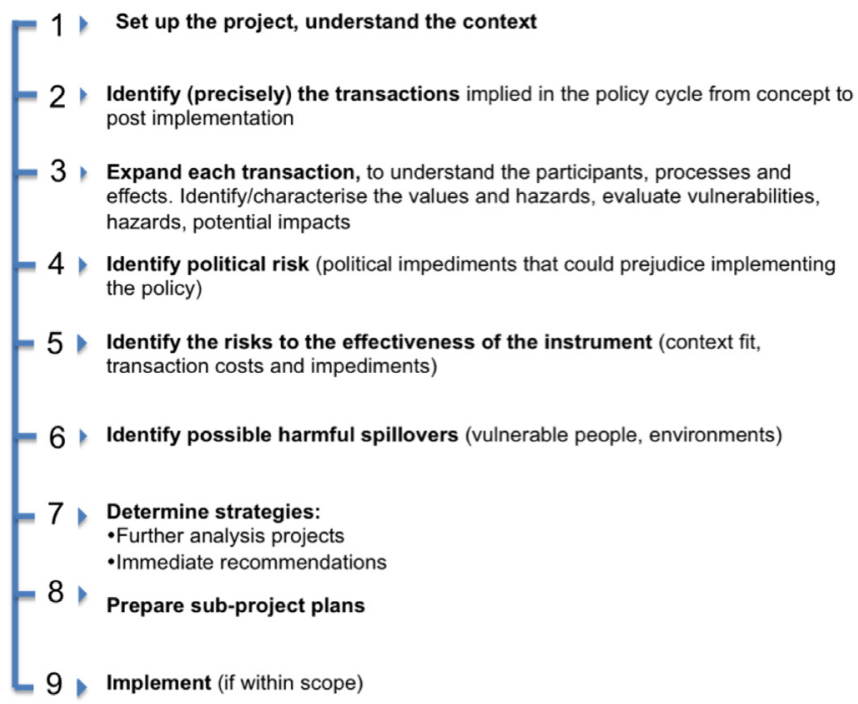

Figure 1: $\quad$ Overview of policy risk process.

The policy risk process is a 'how to guide' for the policy practitioner to undertake either preliminary desktop review or complete analysis of the risks of policy proposals for: political opposition or resistance, failure due to poor instrument design and social and environmental spillovers. The methodology was developed through the merging of risk processes from the 'Risk Governance Framework' [32]; 'AS/NZS 4360:2004 Risk Management' [33] and theoretical underpinnings [31]. Whilst none of the processes reviewed concentrated specifically on risks of political failure, instrument design error or the risk:risk components of environmental policy, collectively they served to frame the approach. The methodology focuses on the scoping aspect of risk assessment with an emphasis on the three forms of policy risk. This process requires that a team explore possible combinations of hazards, the vulnerability of the various risk targets, and the uncertainty that arises about the extent of value that might be lost should the hazard crystallize and have an impact. Policy risk assessment involves systematic deconstruction of assumptions, and a purposeful scepticism about what might go wrong with a policy, and who might be harmed. Concerns for social justice are paramount in policy risk assessment to ensure hazards to the most vulnerable in our community are identified. Risk management is concerned with reducing vulnerability to hazards (by improved robustness or resilience), reducing hazards, and reducing the probability of excessive loss of value. All risk management involves the basic choices of whether to ignore the risk; 'self- 
insure' or absorb the risk by deciding to take no further management action; avoid it; or manage it. Each of these involves a cost, and policy risk management is no different. Policy risk analysis need to 'unbundle' the values, the sensitivities and the vulnerabilities of groups who may be affected by environmental risks, and by the proposed policy interventions. The management strategies that arise include adjustment to the hazards, the harm probabilities, the potential impacts, and the resilience of the adversely affected people. Instruments to manage the various forms of policy risk are also different to general policy mechanisms. Management of political risk can involve political actions to reduce the possibility that a policy will be frustrated, or possible selection of 'second best' options when the political impediments for 'first best' are too great. Management of instrumental risk required risk reduction methods to reconsider the design and implementation arrangements. Management of spillover risks requires strategies to reduce vulnerability, and to facilitate recovery in the event that a hazard eventuates.

\section{Conclusion}

There are two benefits of policy risk assessment, firstly the methodologies for risk analysis focus on un-bundling the beliefs, sensitivities and vulnerabilities of people and the values that may be affected by the policy. Secondly, the strategies that arise from careful risk assessment are additional to those that arise from environmental strategy per se, including hazard reduction, probability reduction, and adjustment to the resilience or robustness of the adversely affected interests. Risk methods can be tedious, however proper risk assessment provides a useful tool to avoid policy failures causing adverse impacts on communities and the environment.

\section{References}

[1] United Nations. World Population Prospects: The 2010 Revision. 2012 [cited 2012 October 28th]; Available from: http://esa.un.org/wpp/ Analytical-Figures/htm/fig_1.htm.

[2] Brown, R.L., Rescuing a planet under stress and a civilisation in trouble 2003, New York USA: Norton \& Company.

[3] Bigas, H., et al., The Global Water Crisis: Addressing an Urgent Security Issue. Papers for the InterAction Council, 2011-2012., T.S. Axworthy, Editor 2012, The United Nations University - Institute for Water, Environment and Health Hamilton, Canada.

[4] Varghese, S. U.S. Water Policy Still All Wet. 2012 [cited 2012 October 26th]; Available from: http://www.fpif.org/articles/us_water_policy_ still_all_wet.

[5] de Gorter, H. and D.R. Just, The Social Costs and Benefits of Biofuels: The Intersection of Environmental, Energy and Agricultural Policy. Applied Economic Perspectives and Policy 2010. 32(1): p. 4-32. 
[6] Ford Runge, C., The browning of biofuels - the political economy of policy failure. World Politics Review, 2010 (February 16th): p. 9-11.

[7] McCarthy, D.P., et al., Financial Costs of Meeting Global Biodiversity Conservation Targets: Current Spending and Unmet Needs Science, 2012. 1229803.

[8] Paloniemi, R., et al., Biodiversity conservation across scales: lessons from a science-policy dialogue. Nature Conservation, 2012. 2.

[9] IAASTD: International Assessment of Agricultural Knowledge, Agriculture at a Crossroads: The Synthesis Report, 2008, IAASTD: Washington, DC, USA.

[10] FAO, The State of Food Insecurity in the World: How does international price volatility affect domestic economies and food security? 2011, Food and Agriculture Organisation of the United Nations: Rome.

[11] Biswas, A.K., Integrated Water Resources Management: Is it working? Water Resources Development, 2008. 24(1): p. 5-22.

[12] Savenlje, H.H.G. and P. van der Zaag, Water as an economic good and demand management: Paradigms with pitfalls. Water International, 2002. 27(1): p. 98-104.

[13] Mainuddin, M., M. Kirby, and M. Ejaz Qureshi, Integrated hydrological economic modeling for analyzing water acquisition strategies in the Murray Darling River Basin. Agricultural Water Management, 2007. 93(3): p. 123135.

[14] Yu-Ting Lee, L. and T. Ancev, A river of funding, a trickle of achievement. Agenda, 2009. 16(1): p. 5-24.

[15] Martin, P.V., Water Law: Through the Lens of Conflict. International Journal of Rural Law and Policy, 2011. 1 (Special edition): p. 1-7.

[16] Qun, D., New developments in water pollution law and policy in China: effective enough to cope with water pollution conflict? International Journal of Rural Law and Policy, 2011. 1 (Special edition): p. 8-23.

[17] Benson, R.D., Public on Paper: The failure of law to protect public water uses in the Western United States. International Journal of Rural Law and Policy, 2011. 1 (Special edition): p. 24-37.

[18] Fort, D., Too hot to handle: climate change and agricultural water use. International Journal of Rural Law and Policy, 2011. 1 (Special edition): p. 50-63.

[19] Tafur, V.M., Water law, mining and hydro-energy conflicts in South America: Tales from the Andes and Patagonia. International Journal of Rural Law and Policy, 2011. 1 (Special Edition): p. 38-49.

[20] Kidd, M., Poisoning the right to water in South Africa: what can the law do? International Journal of Rural Law and Policy, 2011. 1 (Special edition): p. 78-95.

[21] Martin, P.V. and J. Becker, A tale of two systems: conflict, law and the development of water allocation in two common law jurisdictions. International Journal of Rural Law and Policy, 2011. 1 (Special edition): p. 96-115. 
[22] Haraldsdottir, K., Property rights in water and social conflict: an example from Iceland. International Journal of Rural Law and Policy, 2011. 1 (Special Issue): p. 64-77.

[23] Jeffrey, M. and D. Craig, Application of environmental conflict resolution to public interest issues in water disputes. International Journal of Rural Law and Policy, 2011. 1 (Special edition): p. 135-148.

[24] Paisley, R.K. and A. Grzybowski, Some reflections on the resolution of state-to-state disputes in international waters governance agreements. International Journal of Rural Law and Policy, 2011. 1 (Special edition): p. 116-134.

[25] Australian Government. National Water Market. 2012 [cited 2012 October 31st 012]; Available from: http://www.nationalwatermarket.gov.au/how-totrade/index.html.

[26] National Water Commission, Australian environmental water management: 2012 Review, 2012: Canberra.

[27] Martin, P.V., Developing the Guide to the Proposed Basin Plan: peer review reports Appendix J, 2010, Murray Darling Basin Authority: Canberra.

[28] Murray Darling Basin Authority, Guide to the Proposed Basin Plan, 2010, Murray Darling Basin Authority: Canberra.

[29] Wikipedia. Roman triumph. 2012 [cited 2012 3rd November 2012]; Available from: http://en.wikipedia.org/wiki/Roman_triumph.

[30] Martin, P.V. and J.A. Williams, The Water Act: Hubris without sufficient legal safeguards? 2012, Australian Centre for Agriculture and Law.

[31] Martin, P.V. and J.A. Williams, Policy Risk Assessment, 2010, CRC for Irrigation Futures: Richmond NSW.

[32] International Risk Governance Council, White Paper on Risk Governance: towards an integrative approach, 2006: Geneva.

[33] Standards Australia, Risk Management AS/NZS 4360:2004, 2004: Strathfield NSW. 